\title{
A Histopathological Study on Motile Aeromonad Disease of Crucian Carp
}

\author{
Teruo MIYAZAKI*1 and Noboru KAIGE*2 \\ ${ }^{* 1}$ Faculty of Fisheries, Mie University, \\ 2-80, Edobashi, Tus, Mie 514, Japan \\ ${ }^{* 2}$ Chusei Livestocl Hygiene Service Center, Takajaya \\ Tsu, Mie 514, Japan
}

(Received March 6, 1986)

\begin{abstract}
Outbreaks of motile aeromonad disease occurred among crucian carps, Carassius auratus, in game-fish ponds. Aeromonas hydrophila which produced strong $\beta$-hemolysin was isolated from the diseased fish. A histopathological study was made on the infected fish. The fish showed hemorrhage on the body surface, accumulation of red-colored ascitic fluid and enteritis with bacterial invasions. Hemosiderosis was observed in the liver, spleen and kidney. Deposition of hematoidin crystals was found in the spleen, kidney and blood vessels. Experimental infections were carried out by intraperitoneal injection with the isolate into crucian carp and resulted in manifestation of similar pathological signs to those of the naturally infected case.
\end{abstract}

Aeromonas hydrophila was known to produce toxic substances evoking hemorrhage and necrosis (Shimizu 1969, a, b; Allan and Stevenson, 1981; WAKABAYASH et al., 1981; KANAI and WAKABAYASHI, 1984). Those in vivo and in vitro studies confirmed the bacterial toxin including enzymes such as protease and elastase. This bacterium also produces $\beta$-type hemolysin on blood agar plates (EGUSA, 1978). An infection of $A$. hydrophila producing strong $\beta$-hemolysin was found among crucian carps, Carassius auratus, kept in game-fish ponds in Osaka Prefecture in the spring of 1985 . Diseased fish showed heavy hemorrhage on the body surface and accumulation of red-colored ascitic fluid. Experimental infections were carried out by intraperitoneal injection with the isolate into crucian carps. A histopathological study was made on both naturally and experimentally infected cases.

\section{Materials and Methods}

Five crucian carps (about $15 \mathrm{~cm}$ in body length) with motile aeromonad disease were taken from game-fish ponds in Osaka Prefecture in the spring of 1985. After external and internal observation of diseased fish, bacterial isolation was tried from ascitic fluid and the liver with BHI agar plates (Nissui), and the visceral organs and lateral musculature were fixed in $10 \%$ formalin solution. Bacteriological tests were carried out for identification of the isolates. Five crucian carps (about $10 \mathrm{~cm}$ in body length) were infected by intraperitoneal injection with $10^{7} \mathrm{CFU} / 100 \mathrm{~g}$ of one strain of the isolates after 24 hour incubation on $\mathrm{BHI}$ agar plates at $25^{\circ} \mathrm{C}$. Injected fish were kept in a 50 liter plastic aquarium at $25^{\circ} \mathrm{C}$ water temperature. When injected fish were moribund, they were taken for external and internal observation, bacterial isolation and fixation of the visceral organs and musculature in the same way as in the naturally infected fish.

Fixed materials were processed routinely and 3-5 $\mu \mathrm{m}$ sections were stained with Mayer's hematoxylin and eosin (H-E), Giemsa, PAS, Berlin blue, $3 \% \mathrm{H}_{2} \mathrm{O}_{2}$ treatment post-stain with Berlin blue, Okamoto-Hiroya's method, Sudan black B and Ziehl-Neelsen's method.

\section{Results}

1. External and internal signs, bacterial isolation

All naturally infected fish showed hemorrhage and erosious patches on the body surface and 
abdominal expansion. Accumulation of redcolored ascitic fluid in the body cavity and enteritis were also observed. The liver, spleen and ovaries showed yellowish red-coloration. Bacteria were purely isolated from the ascitic fluid and livers, forming many colonies on BHI agar plates. The isolates produced a $2-3 \mathrm{~mm}$ wide clear zone of $\beta$-type hemolysis on sheep blood agar plates after 24 hour incubation at $25^{\circ} \mathrm{C}$.

All experimentally infected fish became moribund in 2-3 days, showing hemorrhage on the body surface, slight accumulation of red-colored ascitic fluid, and pale-coloration of livers and spleens. The bacteria were reisolated from the liver of moribund fish.

Based on bacteriological tests the isolated bacteria were identified as $A$. hydrophila.

\section{Histopathological findings}

In naturally infected fish, the intestines showed extensive desquamative catarrh accompanied by necrosis of the villi with extensive bacterial invasions in the epithelium, tunica propria and submucosa (Fig. 1). Bacterial multiplication was observed in the packed matter inside the intestine. Moreover, the bacerial invasions were found diffusely in the omentum, capsules of the liver and spleen, and fibrin deposited on the omentum (Fig. 2). The livers showed extensive deposition of hemosiderin in atrophic hepatic cells and macrophages in the interstitial tissues (Fig. 3). The hemosiderin was observed as fine granules in hepatic cells and small lumps in macrophages, stained blue with Berlin blue. The spleens displayed extensively deposition of hematoidin crystals and accumulation of hemosiderin-laden macrophages in the pulps (Fig. 4). Hematoidin crystals shaped quartz-like crystals of various sizes being neither branch nor segment. Hematoidin crystals were observed to have developed radially or to be tied up in bundles. The crystals showed yellow or brown-color in the unstained section, and were stained blus with OkamotoHiroya's method and negative with H-E, Berlin blue, $3 \% \mathrm{H}_{2} \mathrm{O}_{2}$ treatment post-stain with Berlin blue, PAS, Ziehl-Neelsen's method and Sudan black B. They were not decolored by treatment with $3 \% \quad \mathrm{H}_{2} \mathrm{O}_{2}$ and organic solvents. Such hematoidin crystals were also found to be formed in blood vessels (Fig. 5) and the cardiac lumen, and on the omentum, which were shorter and thinner than those in the spleens. The kidney showed hematoidin deposition and infiltration of hemosiderin-laden macrophages in the hematopoietic tissues (Fig. 6). Tubular epithelial cells displayed cloudy swelling, hyaline droplet degeneration and slight necrosis. Capillaries of glomeruli were degenerated. Hemosiderin-laden macrophages infiltrated into the ovaries, in which most ovarian and egg cells were degenerated. It was difficult to observe the bacterial migration inside the liver, spleen, kidney, heart, blood vessels and ovaries with microscopy.

Experimentally infected fish showed hemosiderin deposition in atrophied hepatic cells and macrophages migrating into the liver, spleen and hematopoietic tissue. Slight formation of hematoidin crystals in the splenic pulps and hyaline droplet degeneration of renal tubular epithelia were found.

\section{Discussion}

Many reports indicated $A$. hydrophila produced toxic substances including hemolysin, protease and elastase (Hoshina, 1962; SHimizu, 1969a, b; Wolke, 1975; EguSA, 1978; HuIZiNGa et al., 1979; Allan and Stevenson, 1981; WaKaBAYASHI et al., 1981; KANAI and WAKABAYASHi, 1984). Pathology of this bacterial disease was characterized by either septicemia (AFS, 1975) or toxemia (MIYAZAKI, 1980; MIYAZAKI and Jo, 1985). These studies showed clearly that toxic substances of this bacterium played important roles in causing exudation, hemorrhage, cellular degeneration and tissue necrosis. In crucian carps, exudation, cellular degeneration and tissue necrosis were observed. These pathological changes indicated that the infected fish were in toxemia. It is generally known that $A$. $h y$ drophila produces $\beta$-hemolysin (HosHINA, 1962; MCCARThy, 1975). Hoshina (1962) showed hematologically an increase in the number of ghost cells indicating hemolysis in the circulating blood of Japanese eels with A. hydrophila infection. In this study, crucian carps were infected with $A$. hydrophila which produced strong $\beta$-hemolysin on blood agar plates. It was demonstrated by SUZUE and KoBAYASHI (1974) that when hemolysis occurred in vivo, hematoidin 
crystals and hemosiderin usually deposited in tissues and migrated macrophages. Histochemical characteristics of hematoidin crystals were shown in detail by Suzue and KobaYashi (1974). Histochemical characteristics of hematoidin crystals of crucian carps observed in this study were almost corresponded with those described by Suzue and Kobayashi (1974). This study indicated that the infection of strong $\beta$-hemolytic strains of $A$. hydrophila could cause hemolysis inside the fish body, followed by deposition of hematoidin crystals and hemosiderin.

\section{Acknowledgment}

The authors wish to thanks Professor Hisatsugu WAKABAYASI of University of Tokyo for valuable advice and help for bacterial identification.

\section{References}

AFS (American Fisheries Society, Fish Health Section) (1975): Suggested procedures for the detection and idenfication of ceratin infectious diseases. U.S. Fish. Wildl. Serv., Washington, D.C.

Allan B. J. and R. M. W. Stevenson (1981): Extracellular virulence factors of Aeromonas hydrophila in fish infections. Canadian J. Microbiol., 27, 11141122.

EguSA, S. (1978): Infectious Diseases of Fishes. Koseisha-Koseikaku, Tokyo, Japan. 554 pp.

Hoshina, R. (1962): Studies on red disease of Japanese eel. J. Tokyo Univ. Fish., 6(1), 1-104.

Huizinga, W. A., G.W. Esch and T. C. Hazan
(1979): Histopathology of red sore disease (Aeromonas hydrophila) in naturally and experimentally infected largemouth bass. J. Fish Dis., 2, 263-277.

KanaI, K. and H. WaKabayashi (1984): Purification and some properties of protease from Aeromonas hydrophila. B. Jap. Sco. Sci. Fish., 50(8), 1367-1374.

MCCARTHY, D. H. (1975): The bacteriology and taxonomy of Aeromonas liquefaciens. Tech. Rep. Ser., 2, 107.

MiYAZAKI, T. (1980): Histopathological study on bacterial infections in fishes. B. Fac. Fish., Mie Univ., 7, 63-149.

MIYAZAKI, T. and Y. Jo (1985): A histopathological study of motile aeromonad disease in ayu. Fish Path., 20(1) 55-59.

Shimizu, T. (1969a): Studies on pathogenic properties of Aeromonas liquefaciens-I. Production of toxic substance to eel. B. Jap. Soc. Sci. Fish., 35(1), 55-66.

ShImizu, T. (1969b): Studies on pathogenic properties of Aeromonas liquefaciens-II. Separation of toxic factors by gel filtration. B. Jap. Soc. Sci. Fish., 35(2), 163-171.

Suzue, K. and T. Kobayashi (1974): Pathology. Igaku-Shoin, Tokyo Japan. 959 pp.

WaKabayashi, H., K. KanaI, I. Hsu and S. Egusa (1981): Pathogenic activities of Aeromonas hydrophila biovar hydrophila (Chester) PoPOFF and Veron, 1976 to fishes. Fish Path., 15(3/4), 319325.

WOLKE, R. E. (1975): Pathology of bacterial and fungal diseases affecting fish. p. 33-116. Edi. by Ribelin W. E. and G. Migaki. The Pathology of Fishes. Univ. of Wasconsin Press, Madison. London, $1004 \mathrm{pp}$. 


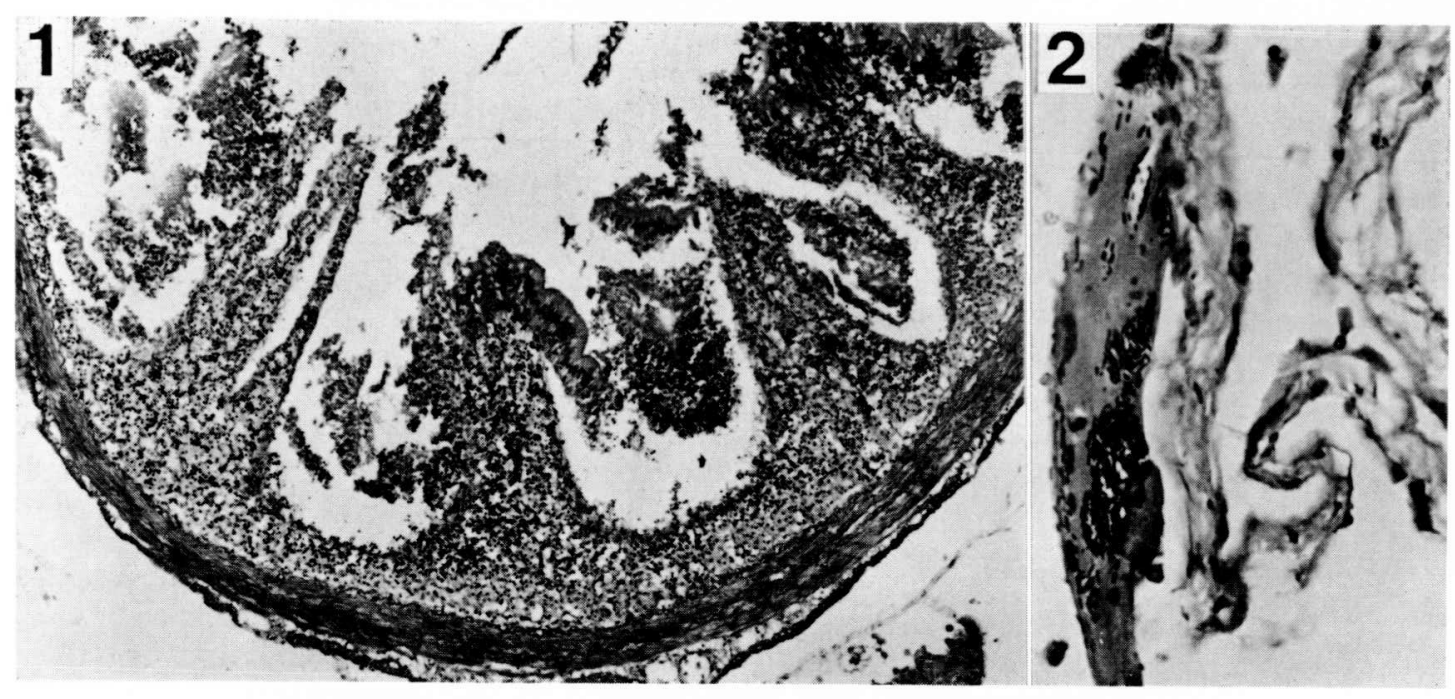

\section{Explanation of Figures}

Fig. 1. Intestine showed desquamative catarrh with necrosis of epithelium, tunica propria and sumbucosa. $\mathrm{H}-\mathrm{E}, \times 50$.

Fig. 2. Bacterial migration into deposited fibrin on omentum. Giemsa, $\times 320$.

Fig. 3. Liver showed deposition of hemosiderin (black granules) in atrophied hepatocytes and accumulated macrophages $(\mathrm{M})$. Berlin blue, $\times 160$.

Fig. 4. Spleen showed deposition of hematoidin crystals shaping quartz-like in pulps and accumulation of hemosiderin-laden macrophages $(M)$. Berlin blue, $\times 160$.

Fig. 5. Abdominal vein displayed deposition of hematoidin crystals in the lumen. Berlin blue, $\times 160$.

Fig. 6. Kidney showed deposition of hematoidin crystals in the hematopoietic tissue. Renal epithelial cells displayed necrosis (arrow) and hyaline droplet degeneration (H). Berlin blue, $\times 160$. 


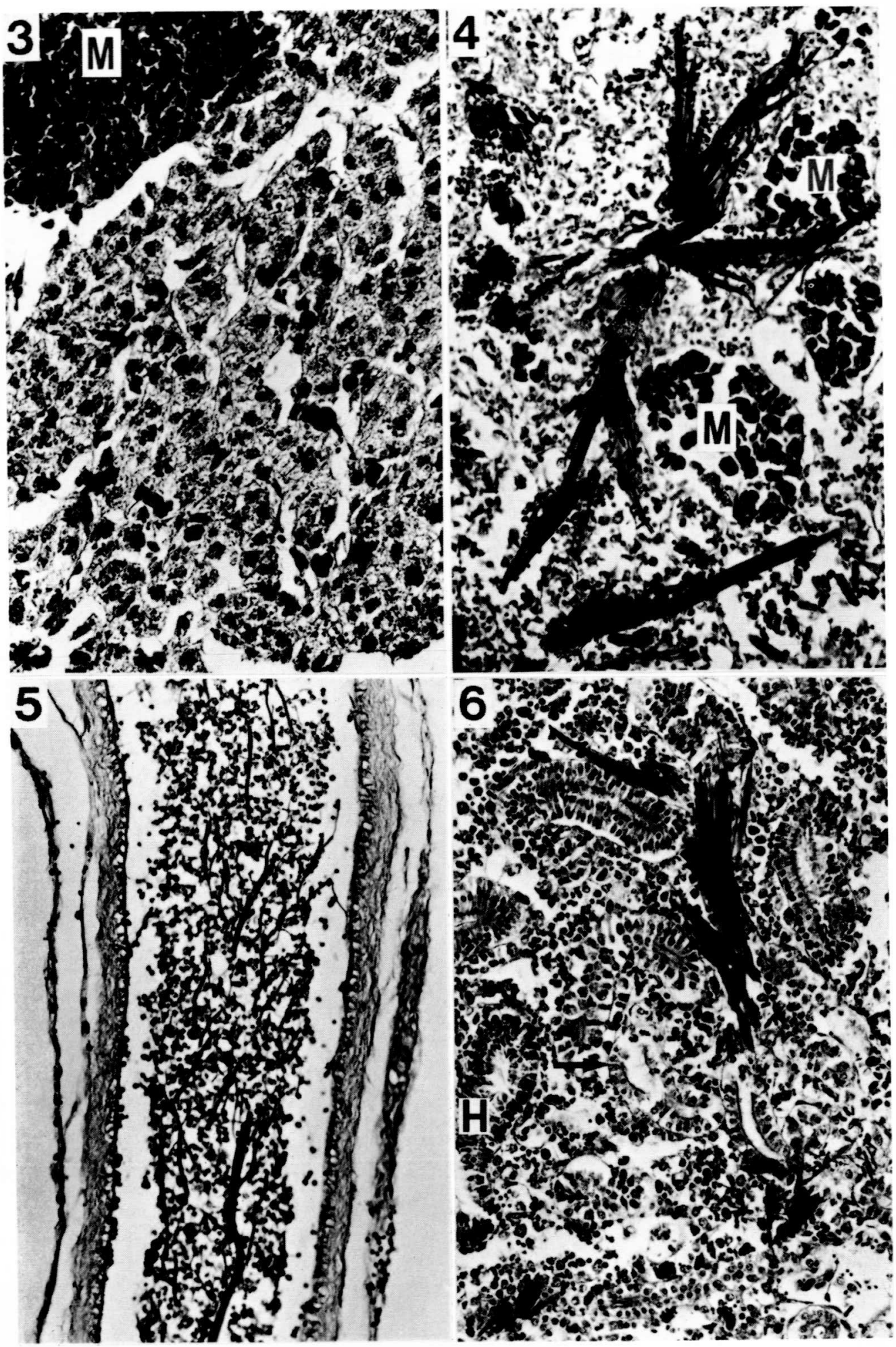

